\title{
C-C motif chemokine receptors in gastric cancer (Review)
}

\author{
HYEWON RYU ${ }^{*}$, SEUNG WOO BAEK ${ }^{*}$, JI YOUNG MOON ${ }^{1}$, IN-SOOK JO ${ }^{2}$, NAYOUNG KIM ${ }^{2}$ and HYO JIN LEE HN $^{3,4}$ \\ ${ }^{1}$ Department of Internal Medicine, Chungnam National University Hospital; ${ }^{2}$ Department of Medical Science; \\ ${ }^{3}$ Department of Internal Medicine, School of Medicine Chungnam National University and Chungnam National \\ University Hospital; ${ }^{4}$ Cancer Research Institute, Chungnam National University, Daejeon 35015, Republic of Korea
}

Received February 2, 2017; Accepted June 6, 2017

DOI: $10.3892 /$ mco.2017.1470

\begin{abstract}
Gastric cancer is the fifth most common cancer and the third leading cause of cancer-associated mortality worldwide. Despite recent advances in molecular and clinical research, patients with gastric cancer at an advanced stage have a dismal prognosis and poor survival rates, and systemic treatment relies predominantly on traditional cytotoxic chemotherapy. To improve patients' quality of life and survival, an improved understanding of the complex molecular mechanisms involved in gastric cancer progression and treatment resistance, and of its clinical application in the development of novel targeted therapies, is urgently required. Chemokines are a group of small chemotactic cytokines that interact with seven-transmembrane G-protein-coupled receptors, and this interaction serves a crucial role in various physiological processes, including organ development and the host immune response, to recruit cells to specific sites in the body. There is also accumulating evidence that chemokines and chemokine receptors (CCRs) contribute to tumor development and progression, as well as metastasis. However, research regarding the functional roles of chemokines and their receptors in cancer is dynamic and context-dependent, and much remains to be elucidated, although various aspects have been explored extensively. In gastric cancer, C-C motif CCRs are involved in the biological behavior of tumor cells, including the processes of growth, invasion and survival, as well as the epithelial-mesenchymal transition. In the present review, attention is given to the clinical relevance of C-C motif CCRs in the development, progression, and metastasis of gastric cancer, particularly CCR7 and CCR5, which have been investigated extensively, as well as their potential therapeutic implications.
\end{abstract}

Correspondence to: Professor Hyo Jin Lee, Department of Internal Medicine, School of Medicine Chungnam National University and Chungnam National University Hospital, 282 Munhwa-ro, Jung-gu, Daejeon 35015, Republic of Korea

E-mail: cymed@cnu.ac.kr

${ }^{*}$ Contributed equally

Key words: chemokine, chemokine receptor, gastric neoplasm, tumorigenesis, therapeutic target

\section{Contents}

1. Introduction

2. C-C motif CCR7

3. C-C motif CCR5

4. Therapeutic implications of $\mathrm{C}-\mathrm{C}$ motif CCRs in gastric cancer

5. Conclusion

\section{Introduction}

Gastric cancer is the fifth most common cancer, and the third leading cause of cancer mortality worldwide (1-3). Despite a steady decline in incidence, gastric cancer causes more than 723,000 mortalities annually $(3,4)$. The systemic treatment options for gastric cancer are limited, and patients have a poor oncologic outcome: Patients with stage 4 cancer show a 5-year overall survival rate of $4.0 \%$ (5). The initiation and progression of gastric cancer is a complex multistep process involving genetic and epigenetic aberrations (6,7). An understanding of the molecular pathogenesis of gastric tumorigenesis has resulted in the development of novel treatment options. Trastuzumab (Herceptin ${ }^{\circledR}$ ), a monoclonal antibody against human epidermal growth factor receptor 2 (HER-2; also termed ERBB2), has led to an improvement in progression-free survival and overall survival compared with chemotherapy alone in patients with advanced gastric cancer overexpressing HER-2 in their tumor cells $(8,9)$. Another agent with positive results is ramucirumab $\left(\right.$ CYRAMZA $\left.^{\circledR}\right)$, an antibody targeting vascular endothelial growth factor receptor-2 (10). That treatment represented the first biological therapy administered as a single drug to have elicited a survival benefit in patients with advanced gastric or gastro-esophageal junction adenocarcinoma that has progressed on first-line chemotherapy (11). Despite these advances in the treatment of gastric cancer, the median survival rate of patients with advanced gastric cancer remains unsatisfactory. An improved understanding of the molecular pathways underlying the development, progression and treatment resistance of gastric cancer would therefore yield novel therapeutic opportunities, resulting in an improved quality of life and the prolonged survival of patients.

Chemokines are a group of small chemotactic cytokines that interact with seven-transmembrane G-protein-coupled receptors, and this interaction is involved in organ development, host immune responses and other physiological 
processes that direct cells to specific sites in the body $(12,13)$. Approximately 50 human genes encode chemokine ligands, and $>20$ chemokine receptor (CCR) genes have been identified since the term 'chemokine' was originally introduced in 1992 as an abbreviated form of chemotactic cytokine $(1,14)$. Chemokines are classified into four major groups, namely, CXC, CC, CX3C and C, based on the position of the first two cysteine residues adjacent to the N-terminus, in which ' $\mathrm{C}$ ' represents cysteine and ' $\mathrm{X}$ ' represents a different amino acid $(13,15,16)$. Chemokines and their receptors are either constitutively expressed or are induced by inflammatory cytokines, growth factors, and other external stimuli in numerous cell types, including leukocytes, endothelial cells, fibroblasts, epithelial cells, and cancer cells $(1,17,18)$. There is accumulating evidence that chemokines and CCRs contribute to tumor development and progression, as well as metastasis, in addition to their role in the immune system $(19,20)$. CCRs act as allosteric molecular relays: The chemokine bound to the extracellular domain of the receptor modifies the tertiary structure of the receptor, resulting in activation of heterotrimeric G-proteins via the intracellular domain. Upon receptor binding, downstream signaling is activated, resulting in the production of the second messengers, inositol trisphosphate and diacylglycerol, with subsequent calcium mobilization and activation of extracellular signal-regulated kinases (ERKs) 1 and 2,p38 mitogen-activated protein kinase, phospholipase-C $\beta$, phosphatidylinositol 3-kinase (PI3K), Ras, the Rho family of GTPases, p21-activated kinases, and nuclear factor- $\kappa \mathrm{B}(\mathrm{NF}-\kappa \mathrm{B})(1,21)$.

In cancer, the role of chemokines and their receptors in tumorigenesis is complex and multifaceted, and involves leukocytes, stromal cells, and the cancer cells themselves. In most situations, the majority of chemokines exhibit powerful pro-malignancy effects; however, under certain conditions, chemokines induce the recruitment of leukocytes with anti-tumor activities to exert tumor-suppressive effects (22). For example, the glutamic acid-leucine-arginine (ELR)-expressing CXC chemokine, CXCL8, promotes tumor growth by inducing angiogenesis and chemoattraction of neutrophilic granulocytes. Neutrophils subsequently further promote tumor growth and progression by producing matrix-degrading and angiogenesis-enhancing factors, such as matrix-metalloproteinase-9 and vascular endothelial growth factor, respectively (23-26). In contrast, non-ELR expressing, CXCR3-binding chemokines, such as interferon- $\gamma$ inducible protein-10, are angiostatic proteins, and recruit anti-tumoral lymphocytes (1). Therefore, research into the functional roles of chemokines and their receptors in cancer is dynamic and context-dependent, and much remains to be elucidated, although various aspects have been investigated extensively. In the present review, the roles of $\mathrm{C}-\mathrm{C}$ motif CCRs in the development, progression, and metastasis of gastric cancer are discussed, focusing particularly on CCR7 and CCR5, which have been investigated extensively, as well as their potential therapeutic implications.

\section{C-C motif CCR7}

Among the $\mathrm{C}-\mathrm{C}$ motif CCRs, the role of CCR7 in gastric cancer has been investigated most extensively. Numerous studies have shown that CCR7 is differentially expressed in tumor cells in gastric cancer at the mRNA and protein levels, as well as in the cell membrane in vitro and in vivo (27-37). In addition, CCR7 was detected in tumor-infiltrating lymphocytes and dendritic cells in gastric cancer, as well as in mononuclear cells in Helicobacter pylori gastritis $(35,38)$. Schmausser et al (35) investigated expression of CCR7 during gastric tumorigenesis. As assessed by immunohistochemistry, CCR7 was expressed in gastric epithelial cells in non-inflamed mucosa, $H$. pylori gastritis, intestinal metaplasia and dysplasia, as well as in gastric cancer. The expression of CCR7 in H. pylori gastritis, which is associated with gastric carcinogenesis, was markedly higher compared with that in non-infected mucosa, and the intensity of CCR7 expression in precancerous lesions and gastric cancer was similar to that in the gastric epithelium of H. pylori gastritis. In addition, H. pylori upregulated CCR7 in CCR7-expressing gastric cancer cell lines, whereas no difference in CCR7 upregulation was identified between the $\mathrm{cag}^{+}$ and cag $^{-}$H. pylori strains $(35,39,40)$. Wang et al (32) demonstrated that CCR7 protein expression was significantly higher in gastric cancer compared with peritumoral tissues, and that high levels of CCR7 expression could be induced by loss of Dicer-1 and decreased levels of let-7a microRNA (miRNA) in gastric cancer. In that study, transfection of let-7a miRNA into gastric cancer cells markedly inhibited the expression of functional CCR7, suggesting that miRNA is involved in the regulation of CCR7 expression (32). The expression of CCR7 in gastric cancer was associated with aggressive tumor biology, including the processes of tumor invasion, lymph node metastasis, lymphatic invasion, venous invasion and an advanced stage of cancer (27-29,31,33), and this may be an important prognostic marker for survival in patients with gastric cancer $(28,29,31)$, although contradictory data have also been reported (30).

CCR7 is involved in various biological processes, including the migration, invasion, survival and metastasis of multiple cell types, including cancer cells $(13,41,42)$. The interaction between CCR7 and its ligand, CCL21, induces actin polymerization and pseudopodia formation (43). However, the mechanism by which CCR7 contributes to tumor progression has yet to be fully elucidated. In gastric cancer, CCL21 stimulation induced calcium mobilization and induced a transient increase in intracellular F-actin levels in CCR7-expressing gastric cancer cells, indicating that the morphological changes required for efficient metastasis were induced by the interaction between CCR7 and its ligand (31). In addition, signaling via CCR7 induced chemotactic and invasive responses in CCR7-positive gastric cancer cells, suggesting that functional CCR7 in gastric cancer cells may exert an important role in migration and invasion of gastric cancer. Recently, two groups demonstrated that CCR7 is involved in the epithelial-mesenchymal transition in gastric cancer $(44,45)$. Zhang et al (44) reported that CCR7 induced the epithelial-mesenchymal transition by upregulating Snail, and that Snail signaling was regulated by the ERK and PI3K pathways instead of the Rho pathway, resulting in $\mathrm{G}_{1} / \mathrm{S}$ cell cycle progression, migration and invasion of gastric tumor cells. Ma et al (45) investigated a CCR7-associated mechanism involved in gastric cancer progression, which was predicted on the basis of a bioinformatics analysis and verified in gastric cancer cells and primary tumor tissues. Those authors 
demonstrated that CCR7 contributed to transforming growth factor $\beta 1$ (TGF- $\beta 1$ )-induced epithelial-mesenchymal transition via crosstalk with the $\mathrm{NF}-\kappa \mathrm{B}$ signaling pathway, facilitating lymph node metastasis and tumor progression.

\section{C-C motif CCR5}

CCR5 and its ligand CCL5 [also termed regulated on activation, normal $\mathrm{T}$ cell expressed and secreted (RANTES)] are among the best-studied chemokines. These chemokines exert their major role in inflammatory processes, wherein they induce chemoattraction of various types of leukocytes to sites of infection and injury $(22,46)$. Subsequently, it was revealed that certain strains of human immunodeficiency virus (HIV) utilize CCR5 as a co-receptor for cellular entry $(22,47)$. Several studies have reported tumor-promoting functions of CCR5/CCL5, particularly in breast cancer $(22,48-51)$, whereas, in certain cases, the CCR5/CCL5 system has been revealed to exert anti-tumoral functions $(52,53)$. In breast cancer, for example, several groups demonstrated that the expression levels of CCR5 and CCL5 were higher in metastatic lymph nodes compared with primary tumors, and a high level of intratumoral CCL5 expression was correlated with advanced-stage disease (54-58). In addition, strong pro-malignancy effects associated with a high expression of CCR5/CCL5 in breast cancer was demonstrated (48). In terms of the role of CCR5/CCL5 in gastric cancer, several studies have demonstrated that gastric cancer cells express CCR5 and its ligand in vitro and in vivo (59-62). CCR5 expression, detected in the cell membrane, differs among gastric cell lines, including MKN45, MKN74, and KATO III, at the RNA and protein levels $(60,61)$. The differential expression of CCR5 was confirmed by immunostaining of human gastric cancer tissue, and CCR5 expression was associated with lymph node metastasis and a worse prognosis in patients with gastric cancer $(59,62)$. Furthermore, CCR5 expression was shown to be an independent indicator of a poor prognosis in gastric cancer (62). In addition, Gawron et al (63) reported that a CCR5 haplotype containing the common alleles, IVS1+151 $\mathrm{G}>\mathrm{T}$ (rs2734686) and IVS2+80 C>T (rs1800024), and the minor allele, IVS1+246 A>G (rs1799987), was moderately associated with an increased risk of gastric cancer. It was reported that CCL5/RANTES is produced by gastric cancer cells, and higher serum concentrations of RANTES are associated with more advanced stages of gastric cancer (62). The expression level of RANTES in malignant lymph nodes was higher compared with that in normal lymph nodes in patients with gastric cancer (59). However, the mechanism governing how the CCR5/CCL5 axis contributes to gastric cancer progression has yet to be properly elucidated. Recently, Ding et al (64) reported that CCL5 secreted by tumor-associated macrophages may promote the proliferation, invasion and metastasis of gastric cancer cells. In that study, CCL5 and CD68, which are surface markers of tumor-associated macrophages, were highly expressed in gastric cancer tissue; furthermore, their expression levels were positively correlated with each other. In addition, CCL5 and CD68 expression was significantly associated with the depth of invasion, lymph node metastasis, staging and tumor differentiation. The serum level of CCL5 was also elevated in patients with gastric cancer compared with healthy volunteers. Co-culture of AGS gastric cancer cells with THP-1-derived macrophages enhanced the proliferation, migration and clone-forming ability of the gastric cancer cells, and upregulated CCR5/CCL5 and phosphorylated signal transducer and activator of transcription 3 (p-Stat3) (64), suggesting that Stat3 activation and induction of the CCR5/CCL5 axis could serve a crucial role in gastric tumorigenesis. Okita et al (65) suggested that gastric cancer cells acquire invasive features by co-operating with peripheral blood mononuclear cells, in which CCL5 exerts an important role. Collectively, these data suggest that CCR5/CCL5 serves a role in gastric tumorigenesis.

\section{Therapeutic implications of $\mathrm{C}-\mathrm{C}$ motif CCRs in gastric cancer}

The CCR7 signaling axis is involved in the oncogenic cascade in various cancer types, and is considered to be potentially a novel therapeutic target (66-71). For example, Cuesta-Mateos et al (68) reported that an anti-CCR7 monoclonal antibody effectively eradicated chronic lymphocytic leukemia cells via complement-dependent cytotoxicity, while sparing subsets of T cells in patients with high-risk cytogenetics and/or refractoriness to the drug, fludarabine. Additionally, the activity of this monoclonal antibody was greater compared with that of alemtuzumab, a monoclonal antibody that had shown the highest efficacy in this patient group. This in vitro activity was confirmed in patients refractory to both fludarabine and alemtuzumab (68). Recently, Boyle et al (70) reported further evidence that loss of CCR7 activity either through deletion or pharmacological inhibition markedly decreased the functional pools of stem-like cells in mouse primary tumors, suggesting a mechanism for the tumor-promoting role of this CCR, and suggesting a novel therapeutic intervention targeting cancer stem cells.

In gastric cancer, preclinical data have demonstrated that blocking CCR7 signaling induces antitumor activity in vitro and in vivo. Zhang et al (44) demonstrated that CCR7 contributed to the epithelial-mesenchymal transition via Snail upregulation in gastric cancer, and that blocking the CCR7-Snail axis decreased CCL19-induced cell migration, invasion and proliferation. This suggested CCR7 signaling to be a potential therapeutic target in gastric cancer. In addition, the CCR7 axis mediated the TGF- $\beta 1$-induced epithelial-mesenchymal transition via crosstalk with $\mathrm{NF}-\kappa \mathrm{B}$ signaling, and blocking the CCR7 axis using a CCR7-neutralizing antibody inhibited the effects of TGF- $\beta 1$ (45). Recently, Ruan et al (72) suggested that fluorescent, magnetic nanoparticle-labeled mesenchymal stem cells (MSCs) were able to target gastric cancer cells in vivo via the CCR7/CCL19 axis to inhibit tumor growth during hyperthermia therapy. In that study, gastric cancer cells produced CCL19, which recruited CCR7-expressing MSCs to gastric tumor sites. These data suggested that gastric tumors expressing CCL19 may be targeted during the treatment of hyperthermia via the combination of CCL19 with fluorescent, magnetic nanoparticle-labeled MSCs to attract CCR7-expressing MSCs (72).

The CCR5 signaling axis is a potential therapeutic target in a variety of malignancies, including breast, colorectal carcinoma, and uterine cervical cancer (22,73-76). As such, 
a number of therapeutic strategies have been developed to inhibit CCR5, including small molecules that inhibit CCR5, peptide antagonists, glycosaminoglycan (GAG) mimetics, and antibodies against CCR5, which have been clinically evaluated in humans $(15,22,77)$. The small molecules, maraviroc and vicriviroc, reduced the invasive abilities of breast cancer cells in vitro. Of the two compounds, maraviroc was shown to decrease pulmonary metastasis by basal breast cancer cells in vivo, and to reduce the tumor burden and prolong the survival of mice with hepatocellular carcinoma $(74,78)$. Similarly, another small-molecule CCR5 inhibitor, TAK-779, was identified to reduce infiltration of regulatory $\mathrm{T}$ cells (Tregs) and to reduce tumor size in a pancreatic cancer model in vivo (79). The second group of CCR5 inhibitors comprises peptides, including Met-CCL5 (also termed Met-RANTES). Met-CCL5 was revealed to inhibit cell migration in vitro and to reduce tumor volume in vivo $(22,80)$. The third group of inhibitors comprises GAG mimetics, which serve as 'decoys' of chemokines and bind to their receptors. Of these compounds, OTR4120 and OTR4131 inhibited CCL5-dependent migration and invasion of hepatoma cells in vitro (81). Consistent with this, in gastric cancer, Mencarelli et al (61) reported that inhibition of CCR 5 signaling reduced gastric cancer cell migration and adhesion to explanted murine peritoneum in vitro. Furthermore, administration of maraviroc between days 3-10 following MKN45 cell inoculation in severe combined immunodeficient mice reduced the extent of peritoneal disease and increased the survival rate. Maraviroc treatment also reduced tumor burden in a xenograft model. In that study, CCR5 antagonism was shown to modulate the expression of genes responsible for tumor growth, including interleukin-10 receptor $\mathrm{B}$, hepatocyte growth factor receptor (MET), the homolog of the atypical cadherin gene (FAT1), Nm23-H1, and lymphotoxin $\beta$-receptor (61). Recently, Lin et al (60) reported that saponin DT-13 demonstrated antitumor activity in gastric cancer by modulating CCR 5 signaling. DT-13 inhibited the growth of BGC-823 and HGC-27 cells in a dose-dependent manner, and significantly decreased gastric cancer cell migration by downregulating CCR5, as indicated by the protein and gene expression levels (60).

\section{Conclusion}

Patients with gastric cancer at advanced stages of the disease have a dismal prognosis and a poor quality of life. An improved understanding of the complex molecular mechanisms involved in gastric cancer development, progression and metastasis is required for early diagnosis and to improve the patients' quality of life and survival by developing novel targeted therapies. Chemokines and their receptors are traditionally considered to modulate directional migration of leukocytes to specific sites, and to be involved in host immune modulation and other physiological processes. However, this system is also considered to participate in the initiation, progression and metastasis of malignant diseases via cell proliferation, migration, invasion, survival, and angiogenesis. C-C motif CCRs are widely expressed in various cell types, including leukocytes, endothelial cells, fibroblasts, epithelial cells, and cancer cells, and they contribute to the tumorigenesis of several types of cancer. CCR7 exerts an important role in gastric tumorigenesis, including cell migration, invasion and the epithelial-mesenchymal transition. In addition, accumulating data suggest that CCR7 signaling may be a potential therapeutic target in gastric cancer. CCR5 and its ligand are differentially expressed in gastric cancer, and their expression is associated with aggressive tumor behavior and a poor prognosis. Additionally, targeting CCR 5 could be an attractive strategy for the treatment of gastric cancer. Further research is therefore required to determine the roles of the complex CCR systems in gastric tumorigenesis to facilitate the development of clinical and therapeutic applications.

\section{Acknowledgements}

The present study is supported in part by the Basic Science Research Program through the National Research of Korea (NRF) funded by the Ministry of Education (grant nos. NRF2014R1A1A2059765 and NRF-2017R1D1A1B0404638), a grant from the Korean Health Technology R\&D Project, Ministry of Health and Welfare (grant no. HI15C0789), and a research fund of Chungnam National University.

\section{References}

1. Lee HJ, Song IC, Yun HJ, Jo DY and Kim S: CXC chemokines and chemokine receptors in gastric cancer: From basic findings towards therapeutic targeting. World J Gastroenterol 20: 1681-1693, 2014.

2. Bass AJ, Thorsson V, Shmulevich I, Reynolds SM, Miller M, Bernard B, Hinoue T, Laird PW, Curtis C, Shen H, et al: Comprehensive molecular characterization of gastric adenocarcinoma. Nature 513: 202-209, 2014.

3. Tan P and Yeoh KG: Genetics and molecular pathogenesis of gastric adenocarcinoma. Gastroenterology 149: 1153-1162.e3, 2015.

4. Siegel RL, Miller KD and Jemal A: Cancer statistics, 2016. CA Cancer J Clin 66: 7-30, 2016.

5. Ang YL, Yong WP and Tan P: Translating gastric cancer genomics into targeted therapies. Crit Rev Oncol Hematol 100: 141-146, 2016.

6. Grabsch HI and Tan P: Gastric cancer pathology and underlying molecular mechanisms. Dig Surg 30: 150-158, 2013.

7. Necula LG, Mambet C, Albulescu $\mathrm{R}$ and Diaconu CC: Epigenetics in gastric carcinogenesis: TET genes as important players. J Immunoassay Immunochem 36: 445-455, 2015.

8. Thiel A and Ristimäki A: Targeted therapy in gastric cancer. APMIS 123: 365-372, 2015.

9. Bang YJ, Van Cutsem E, Feyereislova A, Chung HC, Shen L, Sawaki A, Lordick F, Ohtsu A, Omuro Y, Satoh T, et al: Trastuzumab in combination with chemotherapy versus chemotherapy alone for treatment of HER2-positive advanced gastric or gastro-oesophageal junction cancer (ToGA): A phase 3 , open-label, randomised controlled trial. Lancet 376: 687-697, 2010.

10. Lee HJ, Ryu H, Choi YS, Song IC, Yun HJ, Jo DY and Kim S: Just toxicity, or toxicity as a biomarker of efficacy of ramucirumab in breast cancer? J Clin Oncol 33: 2712, 2015.

11. Fuchs CS, Tomasek J, Yong CJ, Dumitru F, Passalacqua R, Goswami C, Safran H, dos Santos LV, Aprile G, Ferry DR, et al: Ramucirumab monotherapy for previously treated advanced gastric or gastro-oesophageal junction adenocarcinoma (REGARD): An international, randomised, multicentre, placebo-controlled, phase 3 trial. Lancet 383: 31-39, 2014.

12. Yun HJ, Ryu H, Choi YS, Song IC, Jo DY, Kim S and Lee HJ: $\mathrm{C}-\mathrm{X}-\mathrm{C}$ motif receptor 7 in gastrointestinal cancer. Oncol Lett 10: $1227-1232,2015$

13. Mburu YK, Wang J, Wood MA, Walker WH and Ferris RL: CCR7 mediates inflammation-associated tumor progression. Immunol Res 36: 61-72, 2006.

14. Kunkel SL, Strieter RM, Lindley IJ and Westwick J: Chemokines: New ligands, receptors and activities. Immunol Today 16: 559-561, 1995 . 
15. Bachelerie F, Ben-Baruch A, Burkhardt AM, Combadiere C, Farber JM, Graham GJ, Horuk R, Sparre-Ulrich AH, Locati M, Luster AD, et al: International union of basic and clinical pharmacology. [corrected]. LXXXIX. Update on the extended family of chemokine receptors and introducing a new nomenclature for atypical chemokine receptors. Pharmacol Rev 66: 1-79, 2013.

16. Sarvaiya PJ, Guo D, Ulasov I, Gabikian P and Lesniak MS: Chemokines in tumor progression and metastasis. Oncotarget 4: 2171-2185, 2013

17. Arya M, Patel HR and Williamson M: Chemokines: Key players in cancer. Curr Med Res Opin 19: 557-564, 2003.

18. Verbeke H, Struyf S, Laureys G and Van Damme J: The expression and role of CXC chemokines in colorectal cancer. Cytokine Growth Factor Rev 22: 345-358, 2011.

19. Verbeke H, Geboes K, Van Damme J and Struyf S: The role of CXC chemokines in the transition of chronic inflammation to esophageal and gastric cancer. Biochim Biophys Acta 1825: 117-129, 2012.

20. Luster AD: Chemokines-chemotactic cytokines that mediate inflammation. N Engl J Med 338: 436-445, 1998.

21. Ali S and Lazennec G: Chemokines: Novel targets for breast cancer metastasis. Cancer Metastasis Rev 26: 401-420, 2007.

22. Weitzenfeld P and Ben-Baruch A: The chemokine system, and its CCR5 and CXCR4 receptors, as potential targets for personalized therapy in cancer. Cancer Lett 352: 36-53, 2014.

23. Vandercappellen J, Van Damme J and Struyf S: The role of CXC chemokines and their receptors in cancer. Cancer Lett 267 226-244, 2008

24. Tazzyman S, Lewis CE and Murdoch C: Neutrophils: Key mediators of tumour angiogenesis. Int J Exp Pathol 90: 222-231, 2009.

25. Strieter RM, Polverini PJ, Kunkel SL, Arenberg DA, Burdick MD, Kasper J, Dzuiba J, Van Damme J, Walz A, Marriott D, et al: The functional role of the ELR motif in CXC chemokine-mediated angiogenesis. J Biol Chem 270: 27348-27357, 1995.

26. Strieter RM, Burdick MD, Gomperts BN, Belperio JA and Keane MP: CXC chemokines in angiogenesis. Cytokine Growth Factor Rev 16: 593-609, 2005.

27. Arigami T, Natsugoe S, Uenosono Y, Yanagita S, Arima H, Hirata M, Ishigami S and Aikou T: CCR7 and CXCR4 expression predicts lymph node status including micrometastasis in gastric cancer. Int J Oncol 35: 19-24, 2009.

28. Deguchi K, Ichikawa D, Soga K, Watanabe K, Kosuga T, Takeshita H, Konishi H, Morimura R, Tsujiura M, Komatsu S, et al: Clinical significance of vascular endothelial growth factors $\mathrm{C}$ and $\mathrm{D}$ and chemokine receptor CCR7 in gastric cancer. Anticancer Res 30: 2361-2366, 2010.

29. Ishigami S, Natsugoe $S$, Nakajo A, Tokuda K, Uenosono $Y$ Arigami T, Matsumoto M, Okumura H, Hokita S and Aikou T: Prognostic value of CCR7 expression in gastric cancer Hepatogastroenterology 54: 1025-1028, 2007.

30. Kwak MK, Hur K, Park DJ, Lee HJ, Lee HS, Kim WH, Lee KU, Choe KJ and Yang HK: Expression of chemokine receptors in human gastric cancer. Tumour Biol 26: 65-70, 2005.

31. Mashino K, Sadanaga N, Yamaguchi H, Tanaka F, Ohta M, Shibuta K, Inoue $\mathrm{H}$ and Mori M: Expression of chemokine receptor CCR7 is associated with lymph node metastasis of gastric carcinoma. Cancer Res 62: 2937-2941, 2002.

32. Wang WN, Chen Y, Zhang YD and Hu TH: The regulatory mechanism of CCR7 gene expression and its involvement in the metastasis and progression of gastric cancer. Tumour Biol 34 $1865-1871,2013$.

33. Yan C, Zhu ZG, Yu YY, Ji J, Zhang Y, Ji YB, Yan M, Chen J, Liu BY, Yin HR and Lin YZ: Expression of vascular endothelial growth factor $\mathrm{C}$ and chemokine receptor CCR7 in gastric carcinoma and their values in predicting lymph node metastasis. World J Gastroenterol 10: 783-790, 2004.

34. Zhou S, Shen Z, Wang Y, Ma H, Xu S, Qin J, Chen L, Tao H Zhen Z, Chen G, et al: CCR7 expression and intratumoral FOXP3+ regulatory $\mathrm{T}$ cells are correlated with overall survival and lymph node metastasis in gastric cancer. PLoS One 8: e74430, 2013

35. Schmausser B, Endrich S, Brändlein S, Schär J, Beier D, Müller-Hermelink HK and Eck M: The chemokine receptor CCR7 is expressed on epithelium of non-inflamed gastric mucosa, Helicobacter pylori gastritis, gastric carcinoma and its precursor lesions and up-regulated by H. pylori. Clin Exp Immunol 139 : 323-327, 2005

36. Chang WJ, Du Y, Zhao X, Ma LY and Cao GW: Inflammation-related factors predicting prognosis of gastric cancer. World J Gastroenterol 20: 4586-4596, 2014
37. Pituch-Noworolska A, Drabik G, Szatanek R, Białas M, Kołodziejczyk P, Szczepanik A, Stachura J and Zembala M: Immunophenotype of isolated tumour cells in the blood, bone marrow and lymph nodes of patients with gastric cancer. Pol J Pathol 58: 93-97, 2007.

38. Chen J, Yang J, Jiang J, Zhuang Y and He W: Function and subsets of dendritic cells and natural killer cells were decreased in gastric cancer. Int J Clin Exp Pathol 7: 8304-8311, 2014.

39. Mégraud F, Bessède $\mathrm{E}$ and Varon $\mathrm{C}$ : Helicobacter pylori infection and gastric carcinoma. Clin Microbiol Infect 21: 984-990, 2015.

40. Fehlings M, Drobbe L, Moos V, Renner Viveros P, Hagen J, Beigier-Bompadre M, Pang E, Belogolova E, Churin Y, Schneider T, et al: Comparative analysis of the interaction of Helicobacter pylori with human dendritic cells, macrophages, and monocytes. Infect Immun 80: 2724-2734, 2012.

41. Moschovakis GL and Förster R: Multifaceted activities of CCR7 regulate T-cell homeostasis in health and disease. Eur J Immunol 42: 1949-1955, 2012.

42. Raju R, Gadakh S, Gopal P, George B, Advani J, Soman S, Prasad TS and Girijadevi R: Differential ligand-signaling network of CCL19/CCL21-CCR7 system. Database (Oxford) 2015: pii: bav106, 2015.

43. Kodama J, Hasengaowa, Seki N, Kusumoto T and Hiramatsu Y: Expression of the CXCR4 and CCR7 chemokine receptors in human endometrial cancer. Eur J Gynaecol Oncol 28: 370-375, 2007.

44. Zhang J, Zhou Y and Yang Y: CCR7 pathway induces epithelial-mesenchymal transition through up-regulation of Snail signaling in gastric cancer. Med Oncol 32: 467, 2015.

45. Ma H, Gao L, Li S, Qin J, Chen L, Liu X, Xu P, Wang F, Xiao H, Zhou S, et al: CCR7 enhances TGF- $\beta 1$-induced epithelial-mesenchymal transition and is associated with lymph node metastasis and poor overall survival in gastric cancer. Oncotarget 6: 24348-24360, 2015.

46. Sallusto F and Baggiolini M: Chemokines and leukocyte traffic. Nat Immunol 9: 949-952, 2008.

47. Hughes A and Nelson M:HIV entry: New insights and implications for patient management. Curr Opin Infect Dis 22: 35-42, 2009.

48. Soria $\mathrm{G}$ and Ben-Baruch $\mathrm{A}$ : The inflammatory chemokines CCL2 and CCL5 in breast cancer. Cancer Lett 267: 271-285, 2008.

49. Lazennec $\mathrm{G}$ and Richmond A: Chemokines and chemokine receptors: New insights into cancer-related inflammation. Trends Mol Med 16: 133-144, 2010

50. Mantovani A, Savino B, Locati M, Zammataro L, Allavena P and Bonecchi R: The chemokine system in cancer biology and therapy. Cytokine Growth Factor Rev 21: 27-39, 2010.

51. Balkwill FR: The chemokine system and cancer. J Pathol 226: 148-157, 2012.

52. González-Martín A, Gómez L, Lustgarten J, Mira E and Mañes S: Maximal T cell-mediated antitumor responses rely upon CCR5 expression in both CD4(+) and CD8(+) T cells. Cancer Res 71: 5455-5466, 2011

53. González-Martin A, Mira E and Mañes S: CCR5 as a potential target in cancer therapy: Inhibition or stimulation? Anticancer Agents Med Chem 12: 1045-1057, 2012.

54. Lin S, Wan S, Sun L, Hu J, Fang D, Zhao R, Yuan S and Zhang L: Chemokine $\mathrm{C}-\mathrm{C}$ motif receptor 5 and $\mathrm{C}-\mathrm{C}$ motif ligand 5 promote cancer cell migration under hypoxia. Cancer Sci 103: 904-912, 2012.

55. Hartmann MC, Dwyer RM, Costello M, Potter SM, Curran C, Hennessy E, Newell J, Griffin DG and Kerin MJ: Relationship between CCL 5 and transforming growth factor- $\beta 1$ (TGF $\beta 1$ ) in breast cancer. Eur J Cancer 47: 1669-1675, 2011.

56. Zhang Y, Yao F, Yao X, Yi C, Tan C, Wei L and Sun S: Role of CCL5 in invasion, proliferation and proportion of CD44+/CD24phenotype of MCF-7 cells and correlation of CCL5 and CCR5 expression with breast cancer progression. Oncol Rep 21: $1113-1121,2009$.

57. Niwa Y, Akamatsu H, Niwa H, Sumi H, Ozaki Y and Abe A: Correlation of tissue and plasma RANTES levels with disease course in patients with breast or cervical cancer. Clin Cancer Res 7: 285-289, 2001.

58. Yaal-Hahoshen N, Shina S, Leider-Trejo L, Barnea I, Shabtai EL, Azenshtein E, Greenberg I, Keydar I and Ben-Baruch A: The chemokine CCL5 as a potential prognostic factor predicting disease progression in stage II breast cancer patients. Clin Cancer Res 12: 4474-4480, 2006.

59. Cao Z, Xu X, Luo X, Li L, Huang B, Li X, Tao D, Hu J and Gong J: Role of RANTES and its receptor in gastric cancer metastasis. J Huazhong Univ Sci Technolog Med Sci 31: 342-347, 2011. 
60. Lin SS, Fan W, Sun L, Li FF, Zhao RP, Zhang LY, Yu BY and Yuan ST: The saponin DT-13 inhibits gastric cancer cell migration through down-regulation of CCR5-CCL5 axis. Chin J Nat Med 12: 833-840, 2014.

61. Mencarelli A, Graziosi L, Renga B, Cipriani S, D'Amore C, Francisci D, Bruno A, Baldelli F, Donini A and Fiorucci S: CCR5 antagonism by maraviroc reduces the potential for gastric cancer cell dissemination. Transl Oncol 6: 784-793, 2013.

62. Sugasawa H, Ichikura T, Tsujimoto H, Kinoshita M, Morita D, Ono S, Chochi K, Tsuda H, Seki S and Mochizuki H: Prognostic significance of expression of CCL5/RANTES receptors in patients with gastric cancer. J Surg Oncol 97: 445-450, 2008.

63. Gawron AJ, Fought AJ, Lissowska J, Ye W, Zhang X, Chow WH, Beane Freeman LE and Hou L: Polymorphisms in chemokine and receptor genes and gastric cancer risk and survival in a high risk Polish population. Scand J Gastroenterol 46: 333-340, 2011.

64. Ding H, Zhao L, Dai S, Li L, Wang F and Shan B: CCL5 secreted by tumor associated macrophages may be a new target in treatment of gastric cancer. Biomed Pharmacother 77: 142-149, 2016.

65. Okita K, Furuhata T, Kimura Y, Kawakami M, Yamaguchi K, Tsuruma T, Zembutsu $\mathrm{H}$ and Hirata $\mathrm{K}$ : The interplay between gastric cancer cell lines and PBMCs mediated by the CC chemokine RANTES plays an important role in tumor progression. J Exp Clin Cancer Res 24: 439-446, 2005.

66. Shi M, Chen D, Yang D and Liu XY: CCL21-CCR7 promotes the lymph node metastasis of esophageal squamous cell carcinoma by up-regulating MUC1. J Exp Clin Cancer Res 34: 149, 2015.

67. Alfonso-Pérez M, López-Giral S, Quintana NE, Loscertales J, Martín-Jiménez P and Muñoz C: Anti-CCR7 monoclonal antibodies as a novel tool for the treatment of chronic lymphocyte leukemia. J Leukoc Biol 79: 1157-1165, 2006.

68. Cuesta-Mateos C, Loscertales J, Kreutzman A, Colom-Fernández B, Portero-Sáinz I, Pérez-Villar JJ, Terrón F and Muñoz-Calleja C: Preclinical activity of anti-CCR7 immunotherapy in patients with high-risk chronic lymphocytic leukemia. Cancer Immunol Immunother 64: 665-676, 2015

69. Somovilla-Crespo B, Alfonso-Pérez M, Cuesta-Mateos C, Carballo-de Dios C, Beltrán AE, Terrón F, Pérez-Villar JJ, Gamallo-Amat C, Pérez-Chacón G, Fernández-Ruiz E, et al: Anti-CCR7 therapy exerts a potent anti-tumor activity in a xenograft model of human mantle cell lymphoma. J Hematol Oncol 6 : 89, 2013.

70. Boyle ST, Ingman WV, Poltavets V, Faulkner JW, Whitfield RJ, McColl SR and Kochetkova M: The chemokine receptor CCR7 promotes mammary tumorigenesis through amplification of stem-like cells. Oncogene 35: 105-115, 2016.
71. Kim SJ, Shin JY, Lee KD, Bae YK, Sung KW, Nam SJ and Chun KH: MicroRNA let-7a suppresses breast cancer cell migration and invasion through downregulation of $\mathrm{C}-\mathrm{C}$ chemokine receptor type 7. Breast Cancer Res 14: R14, 2012.

72. Ruan J, Ji J, Song H, Qian Q, Wang K, Wang C and Cui D Fluorescent magnetic nanoparticle-labeled mesenchymal stem cells for targeted imaging and hyperthermia therapy of in vivo gastric cancer. Nanoscale Res Lett 7: 309, 2012.

73. Cambien B, Richard-Fiardo P, Karimdjee BF, Martini V,Ferrua B Pitard B, Schmid-Antomarchi $\mathrm{H}$ and Schmid-Alliana A: CCL5 neutralization restricts cancer growth and potentiates the targeting of PDGFR $\beta$ in colorectal carcinoma. PLoS One 6: e28842, 2011.

74. Velasco-Velázquez M, Jiao X, De La Fuente M, Pestell TG, Ertel A, Lisanti MP and Pestell RG: CCR5 antagonist blocks metastasis of basal breast cancer cells. Cancer Res 72: 3839-3850, 2012.

75. Velasco-Velázquez M, Xolalpa W and Pestell RG: The potential to target CCL5/CCR5 in breast cancer. Expert Opin Ther Targets 18: 1265-1275, 2014.

76. Che LF, Shao SF and Wang LX: Downregulation of CCR5 inhibits the proliferation and invasion of cervical cancer cells and is regulated by microRNA-107. Exp Ther Med 11: 503-509, 2016.

77. Maeda K, Das D, Nakata H and Mitsuya H: CCR5 inhibitors Emergence, success, and challenges. Expert Opin Emerg Drugs 17: 135-145, 2012.

78. Ochoa-Callejero L, Pérez-Martínez L, Rubio-Mediavilla S, Oteo JA, Martínez A and Blanco JR: Maraviroc, a CCR5 antagonist, prevents development of hepatocellular carcinoma in a mouse model. PLoS One 8: e53992, 2013.

79. Tan MC, Goedegebuure PS, Belt BA, Flaherty B, Sankpal N, Gillanders WE, Eberlein TJ, Hsieh CS and Linehan DC: Disruption of CCR5-dependent homing of regulatory T cells inhibits tumor growth in a murine model of pancreatic cancer. J Immunol 182: 1746-1755, 2009.

80. Robinson SC, Scott KA, Wilson JL, Thompson RG, Proudfoot AE and Balkwill FR: A chemokine receptor antagonist inhibits experimental breast tumor growth. Cancer Res 63: 8360-8365, 2003.

81. Sutton A, Friand V, Papy-Garcia D, Dagouassat M, Martin L, Vassy R, Haddad O, Sainte-Catherine O, Kraemer M, Saffar L, et al: Glycosaminoglycans and their synthetic mimetics inhibit RANTES-induced migration and invasion of human hepatoma cells. Mol Cancer Ther 6: 2948-2958, 2007. 